\title{
MERAWAT LAGU-LAGU DAERAH PAGU UNTUK PEMERTAHANAN BAHASA: ANALISIS EKOLINGUISTIK
}

Preserving Pagu Folksongs for Language Maintenance: An Ecolinguistic Analysis

\author{
Dalan Mehuli Perangin-Angin ${ }^{1}$ dan Novita Dewi ${ }^{2}$ \\ ${ }^{1,2}$ Universitas Sanata Dharma \\ Idalanperanginangin@gmail.com, ${ }^{2}$ novitadewi@usd.ac.id
}

Naskah Diterima Tanggal 3 Maret 2020—Direvisi Akhir Tanggal 15 Oktober 2020—Disetujui Tanggal 20 November 2020 doi: https://doi.org/10.26499/rnh.v9i2.2932

\begin{abstract}
Abstrak
Penelitian ini membahas pemertahanan bahasa Pagu yang dipakai oleh suku Pagu di Halmahera Utara dengan cara merawat kekayaan sastra dalam bahasa tersebut berupa lagu-lagu daerah. Metode deskriptifkualitatif dipakai untuk menganalisis data berupa tiga lagu daerah Pagu dengan perspektif ekolinguistik. Data yang terkumpul dikelompokkan dan diinterpretasikan dengan perspektif teori ekokritik dan kajian serupa yang memanfaatkan analisis ekolinguistik terutama dalam hal memperoleh, menyajikan, dan menganalisis data. Hasil penelitian menunjukkan bahwa pertama, ketiga lagu mengandung nilai-nilai budaya dan adat-istiadat yang menunjukkan jatidiri masyarakat Pagu yang harus dipertahankan. Kedua, analisis ekolinguistik membuktikan kedekatan emosi masyarakat Pagu dengan alam sekitarnya meskipun kadang alam dianggap sebagai perintang. Ketiga, lagu-lagu tersebut dipengaruhi oleh bahasa Ternate dan bahasa daerah lainnya di Halmahera Utara. Akhirnya disimpulkan bahwa interaksi antar pengguna bahasa dan perawatan budaya seperti lagu-lagu rakyat perlu ditingkatkan agar kepunahan bahasa Pagu dapat dicegah.
\end{abstract}

Kata-kata kunci: bahasa Pagu, lagu rakyat, ekolinguistik

\begin{abstract}
This study explores the maintenance of the Pagu language of North Halmahera by caring for the wealth of its literature such as folksongs. The data examined are three Pagu folksongs. The collected data were categorized and interpreted using ecocriticism and related studies particularly in terms of obtaining, presenting, and analyzing them. Using ecolinguistic perspective to analyze the data, the results show that first, all three songs contain cultural values and customs that show the identity of the Pagu community that have to be maintained. Second, ecolinguistic analysis reveals the emotional closeness of the Pagu community with their natural surroundings although nature is sometimes considered to hinder human journey. Third, in terms of distribution, the songs are influenced by Ternate and other regional languages in North Halmahera. Finally, this study concludes interaction among language users and efforts to care for folk songs should continue to prevent the extinction of the Pagu language.
\end{abstract}

Keywords: Pagu language, folksongs, ecolinguistics

How to Cite: Perangin-Angin, D. M. dan Novita Dewi. (2020). Merawat Lagu-Lagu Daerah Pagu untuk Pemertahanan Bahasa: Analisis Ekolinguistik. Ranah: Jurnal Kajian Bahasa. 9(2). 272-286. doi: https://doi.org/10.26499/rnh.v9i2.2932 


\section{PENDAHULUAN}

Pemertahanan bahasa daerah menjadi perhatian pemerintah Republik Indonesia karena adanya kemauan politik sebagaimana tertuang dalam UUD 1945, Pasal 32, yang berbunyi "Negara menghormati dan memelihara bahasa daerah sebagai bagian dari kebudayaan nasional". UU No. 20 tahun 2003 tentang sistem pendidikan nasional juga mengamanatkan pemakaian bahasa daerah, seperti tercantum pada Pasal 33, yang berbunyi "Bahasa daerah dapat digunakan sebagai bahasa pengantar pada awal pendidikan". Pemerintah daerah pun mempunyai kewajiban mengembangkan, membina, dan melindungi bahasa dan sastra daerah, seperti diatur dalam Pasal 42, UU No. 24 tahun 2009, tentang Bendera, Bahasa dan Lambang Negara serta Lagu Kebangsaan, yang berbunyi "Pemerintah daerah berkewajiban mengembangkan, membina dan melindungi bahasa dan sastra daerah". Dengan undang-undang tersebut setiap warga negara di seluruh wilayah NKRI dan pemerintah memiliki kewajiban untuk menghormati dan memelihara budaya, bahasa, dan sastra daerah.

Meskipun pemertahanan bahasa daerah mempunyai landasan hukum yang kuat, masih banyak bahasa daerah yang belum dapat terlindungi dari ancaman kepunahan. Sebuah bahasa akan punah apabila penuturnya berkurang, kehilangan penuturnya, dan akhirnya hilanglah bahasa itu (Lauder, 2011, 2018). Salah satu bahasa yang terancam punah di Indonesia adalah bahasa Pagu di Halmahera Utara (D. Perangin-Angin, 2018). Bahasa ini dipakai oleh suku Pagu, yakni satu dari sembilan suku yang berada di Kabupaten Halmahera Utara, yang berjumlah sekitar 5.200 jiwa. Suku Pagu bermukim di 13 desa, tersebar di lima kecamatan dengan penduduk, suku, dan bahasa yang berbeda-beda. Kondisi permukiman yang tersebar itu di satu pihak merupakan faktor penyampur kebudayaan dan bahasa yang berarti juga pemersatu kebudayaan tetapi di lain pihak merupakan faktor pelemah ketahanan bahasa dan budaya. Komunikasi dalam bahasa Pagu oleh penutur bahasa di desa-desa yang berjauhan tidak mudah. Mereka lebih mudah berbahasa Melayu dialek Ternate atau bahasa Indonesia untuk berkomunikasi dengan penduduk di desa-desa tetangga yang beragam suku dan bahasa ibu (D. Perangin-Angin, 2013; Tondo, 2019).

Menurut sebuah penelitian yang dilakukan oleh Lembaga Ilmu Pengetahuan Indonesia (LIPI) sepanjang 2011-2014 tentang bahasa-bahasa non-Austronesia yang terancam punah di bagian timur Indonesia, ditemukan bahwa bahasa Pagu terancam punah karena makin sedikit penuturnya (D. Perangin-Angin, 2013; Hisyam, M., D. Purwoko, Usman, 2012). Beberapa faktor penyebab kepunahannya antara lain (1) Pemerintah Republik Indonesia mewajibkan penggunaan bahasa Indonesia sebagai bahasa nasional; (2) Kehadiran perusahaan-perusahaan 
multinasional mengundang masyarakat luar untuk bermukim dan berkomunikasi dengan bahasa non-Pagu; (3) Bahasa Pagu tidak memiliki kewibawaan; (4) Peraturan Pemerintah tentang bahasa Pagu yang diajarkan sebagai muatan lokal di sekolah-sekolah tidak berjalan dengan baik; dan (5) Masyarakat kurang memiliki kesadaran bahwa dengan hilangnya bahasa akan hilang pula budaya dan pengetahuan dari para leluhur.

Salah satu cara untuk membentuk martabat bangsa adalah memperluas cakrawala bahasa dan budaya. Dalam bahasa lokal terkandung nilai-nilai budaya lokal yang akan hilang pula jika tidak ada upaya untuk menyelamatkannya. Membuat rekaman (audio ataupun video) dari orang yang masih bisa berbahasa lokal dengan tujuan mendokumentasikan dan mengarsipkannya merupakan salah satu cara untuk mempertahankan suatu bahasa dari kepunahan (Hinton, 2011). Oleh karena itu, upaya penyelamatan bahasa Pagu dapat dimulai dengan mengkaji karya sastra lokal seperti cerita rakyat, peribahasa, dan lagu rakyat. Lagu rakyat merupakan salah satu elemen budaya yang penting untuk diteliti karena kandungan nilai-nilai sosial dan spiritual yang ada di dalamnya. Hal yang sama telah dilakukan untuk bahasa-bahasa lokal di pelbagai penjuru dunia seperti di Pulau Jersey (Johnson, 2015), Spanyol (Rosowsky, 2015), dan Ethiopia (Chala Teresa, G., \& Dagim Raga, 2018), untuk menyebut beberapa saja.

Dalam lagu daerah (lagu rakyat/folksong) ditunjukkan nilai-nilai kebenaran (moralitas), dan pandangan-pandangan tradisional yang biasanya dalam bentuk metafora (perumpamaan) yang diturunkan lintas generasi. Lirik dalam lagu daerah sarat dengan nilai-nilai luhur di samping kekayaan linguistik dan artistiknya. Oleh karena itu, lagu daerah dapat berfungsi sebagai guru moral yang harus dipertahankan di tengah masyarakat internasional yang makin materialistis.

Dilihat dari perkembangannya hingga sekarang, lagu-lagu berbahasa Pagu tidak banyak dinyanyikan. Hal ini antara lain karena bahasa Pagu sendiri juga mengalami kemerosotan dalam hal penggunaan (D. Perangin-Angin, 2013). Lingkungan bahasa (ekologi bahasa) kurang mendukung vitalitas bahasa Pagu. Selain itu, terdapat pula perubahan sosial dan faktor negatif lainnya seperti keengganan generasi muda memakai bahasa daerah karena daya saingnya lemah. Kajian ini akan membahas pemertahanan bahasa Pagu dengan cara merawat kekayaan sastra berupa lagu rakyat dalam bahasa tersebut guna menyelamatkannya dari kepunahan. Lagu-lagu Pagu yang sudah terkumpul dicermati dalam kajian ini dengan pendekatan ekolinguistik. 


\section{LANDASAN TEORI}

\section{Pemertahanan Bahasa}

Istilah pemeliharaan bahasa (language maintenance) menurut Leanne Hinton menunjuk pada upaya untuk mendorong dan memperkuat bahasa yang masih dipakai oleh penutur muda tetapi sudah mulai menunjukkan kemerosotannya (Hinton, 2011, p. 291). Setelah memahami sosok bahasa-bahasa yang terancam punah di Indonesia, Multamia Lauder memakai istilah "pemberdayaan" guna memberi pengertian kepada masyarakat luas akan pentingnya upaya pemertahanan bahasa sebagai salah satu warisan leluhur (Lauder, 2011, p. 4). Warisan leluhur ini sekaligus menunjukkan identitas kesukuan yang secara turun-temurun berdampak pada kepemilikan sumber daya alam tempat mereka menetap (Hisyam, M., Dwi Purwoko, Usman, \& Dalan Perangin-Angin, 2012).

Seiring perkembangan zaman, ratusan bahasa dengan budaya lokalnya akan terancam punah jika tidak ada usaha, dengan berbagai cara, untuk merawat dan melestarikannya (Sunarto, Mukarto, Bismoko, \& Dewi, 2018). Selain itu, pada bahasa dan budaya lokal pulalah terkandung berbagai kearifan lokal. Kebanyakan masyarakat suku yang dekat dengan hutan mempunyai kearifan dalam hal memelihara kelestarian hutan, obat-obatan herbal, cara bercocok tanam, pewarnaan alami, dan sebagainya. Dengan mempelajari dan melestarikan kearifan lokal, bahasa pun secara otomatis ikut terpelihara.

Revitalisasi bahasa Maori dan Hawai, misalnya, dilakukan melalui jalur informal, yakni mempraktikkan bahasa itu di rumah (lihat, misalnya, Albury, 2016; Hinton, 2001). Setelah lebih dari 20 tahun merdeka, Republik Vanuatu menyadari banyaknya perubahan yang diakibatkan oleh globalisasi (McCormick, 2016; Vari-Bogiri, 2005). Penduduk asli Vanuatu memiliki pengetahuan yang detail tentang lingkungan lokal untuk mendukung kehidupan mereka dari generasi ke geearasi yang seluruhnya tersimpan di dalam bahasa lokal. Sebagai bukti komitmen pemerintah dalam pemertahanan bahasa daerah, unit lingkungan pemerintah Vanuatu mendirikan area konservasi lingkungan alam di Espiritu Santo (Guérin, 2008). Departemen Kesehatan membolehkan pengobatan herbal tradisional dan mempromosikan makanan lokal, misalnya (McCarter \& Gavin, 2011).

Melihat kedua contoh pemertahanan bahasa, hal yang sama telah dilakukan untuk menyelamatkan bahasa Pagu di Halmahera Utara dari kepunahan (Hisyam, M., Dwi Purwoko, Usman, \& Dalan Perangin-Angin, 2012). Upaya pemertahanan bahasa Pagu terbantu oleh kepemimpinan tradisional yang kuat, walaupun perubahan sosial melanda mereka. Revitalisasi bahasa Pagu dewasa ini tetap relevan dengan gerakan masyarakat adat yang telah digalakkan 
menyusul dikeluarkannya Putusan Mahkamah Konstitusi No. 35/PUU-X/2012 yang menyatakan bahwa masyarakat adat berhak atas pengelolaan hutan adat yang menjadi ulayatnya. Revitalisasi ini akan mendorong kesadaran masyarakat adat Pagu untuk memperkuat identitas guna mendapatkan dan memanfaatkan hak-hak mereka. Kejelasan budaya, bahasa, adat-istiadat, dan tradisi diperlukan untuk menunjukkan identitas. Karena itu, gerakan adat ini mendorong masyarakat Pagu merevitalisasi bahasa ibu yakni bahasa Pagu sebagai bagian dari upaya penguatan identitas mereka (D. Perangin-Angin, 2013).

Menilik latar belakang tersebut, perlu dilakukan kajian terus-menerus agar bahasa Pagu tetap hidup, antara lain dengan mencermati bagaimana bahasa itu dipakai dalam diskursus sastra yang dekat dengan kehidupan penggunanya misalnya lagu-lagu daerah. Penelitian ini bertujuan mencermati sejumlah lagu daerah dengan teropong teori ekolinguistik.

\section{Ekolinguistik}

Ekolinguistik adalah studi lintas ilmu yang menghubungkan linguistik dan ekologi untuk mencermati adanya saling ketergantungan antara bahasa dan penafsiran tentang lingkungan tempat kita hidup. Berawal dari bapak pendiri 'ekologi bahasa' Einar Haugen yang tertuang dalam makalah klasiknya pada tahun 1971 tentang interaksi antara bahasa tertentu dan lingkungannya, teori ekolinguistik semakin berkembang antara lain karena lingkungan alam yang berubah menuntut kajian linguistik yang berorientasi sosiologis dan ekologis (Eliasson, 2015). Dalam Ecolinguistics: Language, Ecology and the Stories We Live, Stibbe (2015) berpendapat bahwa kita dijejali oleh bermacam narasi yang disebut "Story-we-live-by" atau sebuah kisah yang lewat di benak banyak individu lintas budaya yang tanpa disadari tidak berpihak pada lingkungan. Sebagai contoh, jika menjelang hari raya atau musim liburan penjualan barang-barang meningkat, hal ini dipandang baik; sebaliknya jika menurun, dikatakan bahwa perekonomian sedang lesu. Padahal, dari perspektif ekologi, mungkin lebih baik jika orang menghabiskan waktu bersama teman dan keluarga di rumah atau menjelajah alam daripada menghamburkan uang untuk wisata kuliner atau membagi-bagi hadiah.

Contoh lain penerapan ekolinguistik terlihat pada pemberitaan di media mengenai banjir bandang di Bondowoso di awal tahun ini. Banjir digambarkan dengan kata-kata "menerjang”, "hujan deras mengguyur desa di Lereng Gunung Raung”, "banjir bandang menelan banyak korban jiwa”, dan sebagainya. Di sini alam dianggap kejam, sedangkan manusia dipandang sebagai korban, bukan sebaliknya. Narasi semacam ini bersifat antroposentrik karena berpihak kepada manusia, bukan pada pelestarian alam. 
Tugas Ekolinguistik antara lain mengeksplorasi fenomena linguistik yang ditemukan dalam narasi tentang manusia dan lingkungan sekitarnya dengan perspektif ekosofi, yakni komitmen untuk merawat lingkungan demi keutuhan ciptaan (Nash \& Mühlhäusler, 2014; Steffensen \& Fill, 2014; Stibbe, 2015). Bahasa Pitkern-Norf'k di Pulau Norfolk, misalnya, semakin terkikis karena sejumlah aspek leksikal dan gramatikal sangat bergantung pada kondisi lingkungannya yang berubah cepat (Nash \& Mühlhäusler, 2014). Steffensen \& Fill (2014) mengusulkan kerangka kerja untuk mengaktifkan sinergi antara ekologi dan bahasa, yaitu menentang eksploitasi sumber daya alam, memberdayakan kelompok sosial yang terpinggirkan, dan memastikan bahasa adalah kultur hidup yang harus berdampingan secara damai dalam komunitas multikultural. Tujuan utama ekolinguistik adalah mengembangkan teori linguistik dengan cara melihat manusia sebagai bagian dari masyarakat sekaligus bagian dari ekosistem yang lebih besar yang menjadi sandaran kehidupan (Stibbe, 2015). Selain itu, ekolinguistik menunjukkan bagaimana ilmu linguistik dapat digunakan untuk mengatasi masalah ekologis yang makin mendera, mulai dari perubahan iklim dan hilangnya keanekaragaman hayati hingga keadilan lingkungan. Dengan demikian, ekolinguistik menelisik peran bahasa dalam sebuah interaksi yang menopang kehidupan manusia, spesies lain, dan lingkungan fisik.

\section{METODE PENELITIAN}

Penelitian deskriptif-kualitatif ini memanfaatkan sumber data dari penelitian yang sudah ada, meski terbatas jumlahnya, tentang bahasa Pagu. Sebagian data diambil dari penelitian berjudul "Pemertahanan Bahasa dan Budaya Terancam Punah di Indonesia Timur" oleh LIPI pada 2011-2014 yang beranggotakan salah satu penulis artikel ini. Data primer yang dikumpulkan berupa tiga buah lagu rakyat. Data sekunder terdiri atas artikel jurnal ilmiah, buku-buku, dan pelbagai berita dari surat kabar yang relevan dengan penelitian ini. Data yang terkumpul dikelompokkan dan dimaknai dengan teori ekolinguistik (Nash, 2015; Steffensen \& Fill, 2014; Stibbe, 2015).

\section{PEMBAHASAN}

Lagu-lagu daerah Pagu kebanyakan berasal dari lagu berbahasa Tobelo yaitu bahasa suku yang terbesar di Halmahera Utara, dan sebagian dinyanyikan ulang dalam bahasa Pagu. Lagu pertama "Aba Jou” dinyanyikan oleh penduduk Pagu yang memeluk agama Kristen. Demikian lirik lagu yang berisi pujian kepada Sang Pencipta ini. 


$\begin{aligned} & \text { Aba Jou Ni pareta } \\ & \text { sininga ma }\end{aligned}$
bapak tuhan POSS.2 kuasa
$\begin{aligned} & \text { (Allah Bapa kuasaMu di dalam hati) } \\ & \text { Jou to-ni-suba to-ni-sialene, Aba jou }\end{aligned}$
Tuhan 1-2-puji 1-2-sembah bapak tuhan
(Tuhan aku memujiMu dan menyembahMu, Allah Bapa)

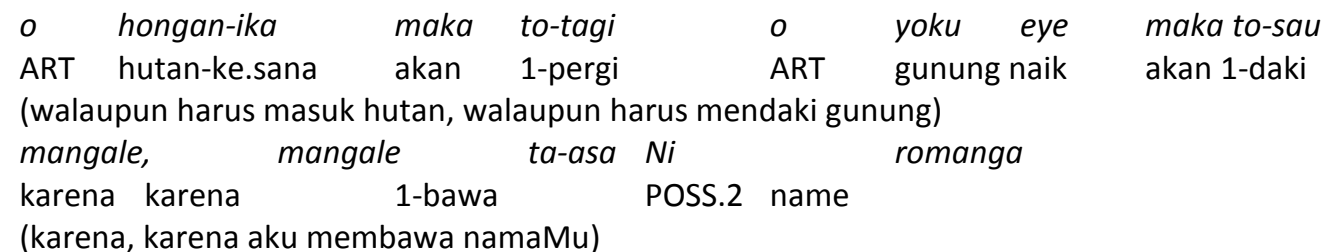

To-ma-siap-ua maka to-tagi o moku-moku i-sese-sese

1-REFL-siap-tidak akan 1-pergi ART ombak-ombak dia-pecah-pecah

(sekalipun aku tidak siap aku akan tetap pergi, sekalipun ombak besar membelah)

mangale, mangale ta-asa $\mathrm{Ni}$ romanga

karena karena 1-bawa POSS.2 name

(karena, karena saya membawa namaMu.)

Pengaruh bahasa Tobelo atau Modole terlihat jelas dalam lagu di atas. Modole adalah nama suku yang letak wilayahnya paling dekat dengan wilayah suku Pagu. Sebagai contoh, dalam lirik lagu tadi terdapat dua kata yang berasal dari bahasa Tobelo/Modole, yaitu honganika dan romanga. Dalam bahasa Pagu sendiri kedua kata itu berturut-turut adalah bonganika yang berarti 'hutan' dan lomanga yang berarti 'nama'.

Analisis Ekolinguistik atas lagu "Aba Jou" menunjukkan bahwa antroposentrisme masih terlihat dalam masyarakat Pagu meskipun mereka hidup dekat dengan alam. Penggunaan konjungsi konsesif walaupun dan konjungsi sebab karena menunjukkan bahwa alam digambarkan sebagai penghalang. Alam kadang tidak mendukung aktivitas manusia. Pengulangan sebanyak masing-masing empat kali untuk kedua jenis kata sandang tersebut makin mempertegas bingkai (framing) yang antroposentrik, yakni alam dapat bertindak sebagai musuh manusia.

(1) o honganika maka totagi o yoku eye maka tosau

(walaupun harus masuk hutan, walaupun harus mendaki gunung)

(2) mangale, mangale taasa Ni romanga (karena, karena aku membawa nama-Mu)

(3) tomasiapua maka totagi o moku-moku isese-sese (sekalipun aku tidak siap aku akan tetap pergi, sekalipun ombak besar membelah)

(4) mangale, mangale taasa Ni romanga

(karena, karena saya membawa nama-Mu)

Pada data (1), (2), dan (3) alam menjadi kekuatan yang harus ditaklukkan. Cerita atau narasi lagu ini menunjukkan seolah-olah hutan, gunung, dan ombak diciptakan Tuhan untuk memenuhi kebutuhan hidup manusia saja. Ketiganya tidak boleh bertindak garang karena ini 
berarti melawan manusia. Terlihat dari data (3) dan (4) bahwa sekalipun manusia tidak siap atau gentar, manusia tetap menjadi pemenang karena membawa nama Tuhan. Dari perspektif ekolinguistik, hutan, gunung, dan ombak berhasil ditaklukkan oleh manusia. Hal ini sejalan dengan semangat "masyarakat adat" yang mau menjaga alam.

Menurut Kingsnorth dan Hine dalam The Dark Manifesto, banyak cerita yang lebih sering dipaparkan tentang sentralitas manusia, yakni spesies yang ditakdirkan untuk menjadi tuan atas semua makhluk. Kisah tentang binatang dan tumbuhan yang mendukung kemaslahatan manusia hampir tidak pernah dituliskan (Kingsnorth \& Hine, 2009). Paparan hubungan antar ciptaan yang tidak seimbang ini mengerikan karena berpusat pada manusia; seakan-akan pelbagai spesies di planet bumi ini diciptakan untuk melayani kebutuhan manusia; dan ketimpangan relasi manusia-alam ini dianggap lumrah.

Narasi yang lebih bersahabat dengan alam diperlihatkan pada lagu kedua "Maluku Miodora" yang bertemakan patriotisme. Meskipun berbeda-beda tetapi hanya ada satu suku di Maluku. Diceritakan dalam lagu ini orang hidup sengsara. Di sini hutan dan pantai bukan penyebab kesengsaraan. Mereka tetap mencintai Maluku seperti berikut ini.

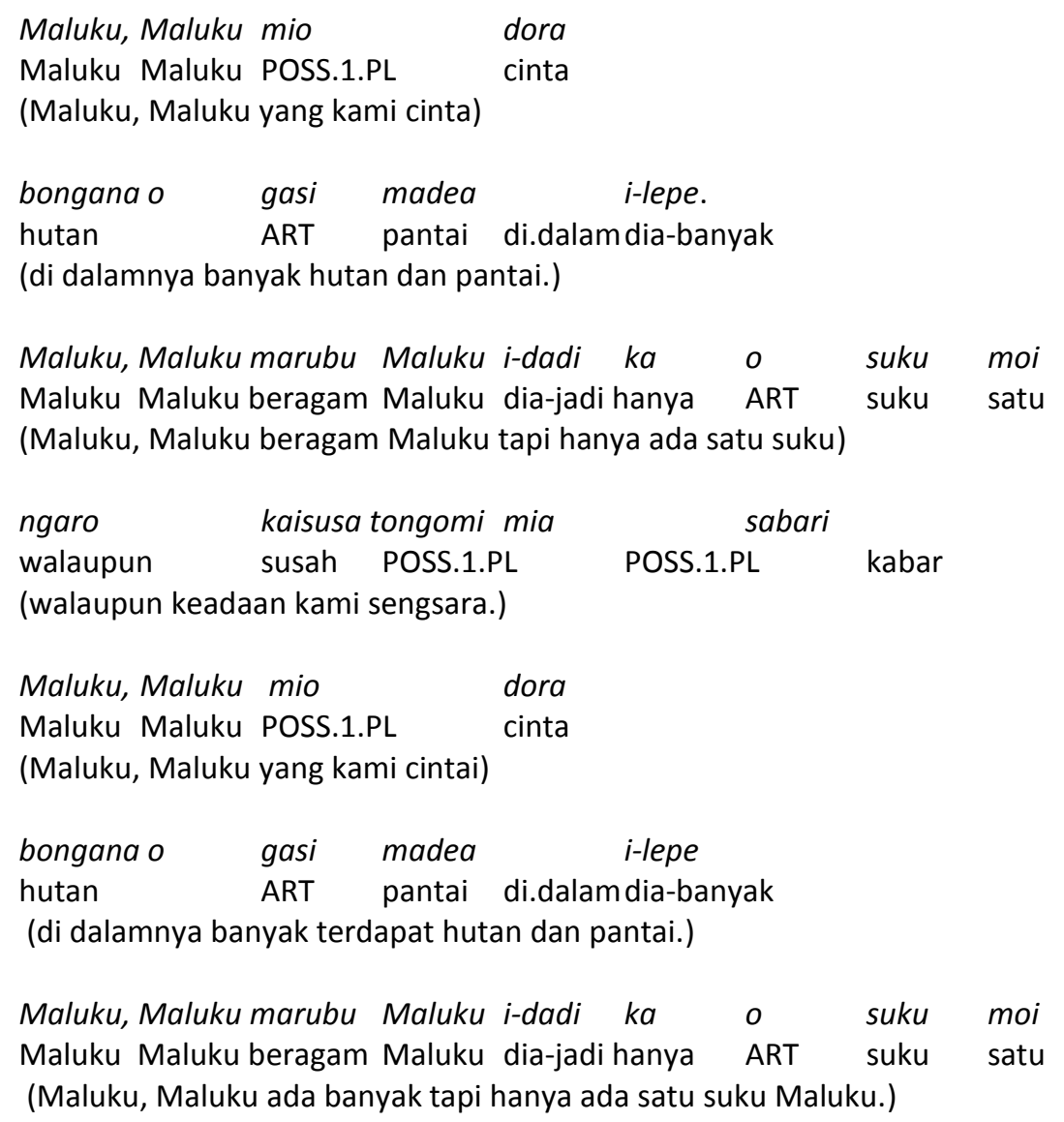




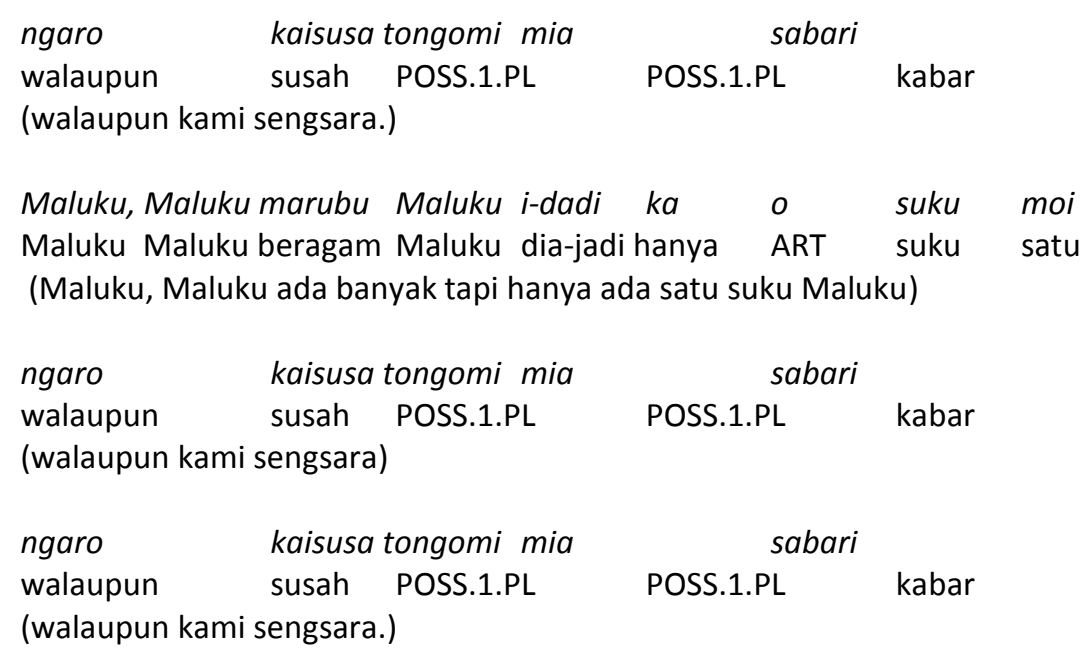

Interaksi antara manusia dan lingkungannya menjadi bahan kajian dalam ekolinguistik. Toponim atau nama tempat, terutama yang berasal dari fitur topografi, merupakan artefak budaya dan lingkungan hidup yang penting yang dimiliki oleh suatu bangsa dan bahasanya (Nash, 2015). Nama Maluku sudah tercatat sejak zaman sejarah kontak dan interaksi antara penduduk lokal dengan pelancong dari Asia Barat, Cina, dan para penjelajah Eropa dalam hal perdagangan rempah-rempah (Amal, 2016; Pattikayhatu, 2012; Ririmasse, 2017). Sejumlah literatur baik ilmiah maupun populer mencatat arti kata Maluku yang berbeda-beda bahkan dalam bahasa daerah Halmahera Utara sendiri. Dalam bahasa Galela, misalnya, maberarti 'sekali' dan luku berarti 'dalam'; sementara dalam bahasa Tobelo terdapat kata loko yang dikenal juga dalam bahasa Ternate yang berarti 'gunung' (Amal, 2016, p. 5), sedangkan dalam wacana populer kata Maluku berasal dari bahasa Arab jazirah al mamluk atau 'kediaman rajaraja' yang diberikan oleh para pedagang Arab yang mendarat di kepulauan yang kaya rempahrempah itu.

Lirik lagu "Maluku Miodora" sarat dengan toponim. Kata Maluku dalam lagu ini muncul sebanyak 14 kali untuk menyangatkan pentingnya Maluku bagi kelompok etnis ini. Pemahaman tentang bumi sebagai kekuatan hidup digerakkan melalui metafora yang menyandingkan hutan (daratan) dengan pantai (laut) sebagai pola dasar kehidupan. Evaluasi tentang alam sebagai penyangga kehidupan ini menurut perspektif ekolinguistik merupakan narasi yang bermakna positif. Evaluasi didefinisikan sebagai "cerita di benak orang tentang apakah suatu wilayah hidup itu baik atau buruk" (Stibbe, 2015, p. 84).

(5) Maluku, Maluku mio dora (Maluku, Maluku yang kami cinta)

(6) bongana o gasi madea ilepe. (di dalamnya banyak hutan dan pantai.) 
(7) Maluku, Maluku marubu Maluku idadi ka o suku moi

(Maluku, Maluku beragam Maluku tapi hanya ada satu suku)

(8) ngaro kaisusa tongomi mia sabari.

(walaupun keadaan kami sengsara.)

Data (5), (6), dan (7) memberikan evaluasi lebih lanjut sekaligus apresiasi bahwa Maluku merupakan tanah yang tak tergantikan. Kata sandang konsesif walaupun pada data (8) justru makin menyangatkan betapa mereka mencintai Maluku.

Lagu terakhir merupakan lagu percintaan muda-mudi. Tema alam atau lingkungan hidup hampir tidak ada. Akan tetapi, analisis ekolinguistik dapat menunjukkan apakah lagu ini berpotensi memperkaya keseimbangan ekologi atau sebaliknya. Lirik lagu ketiga "Sayange Nanga Sejara" disajikan sebagai berikut.

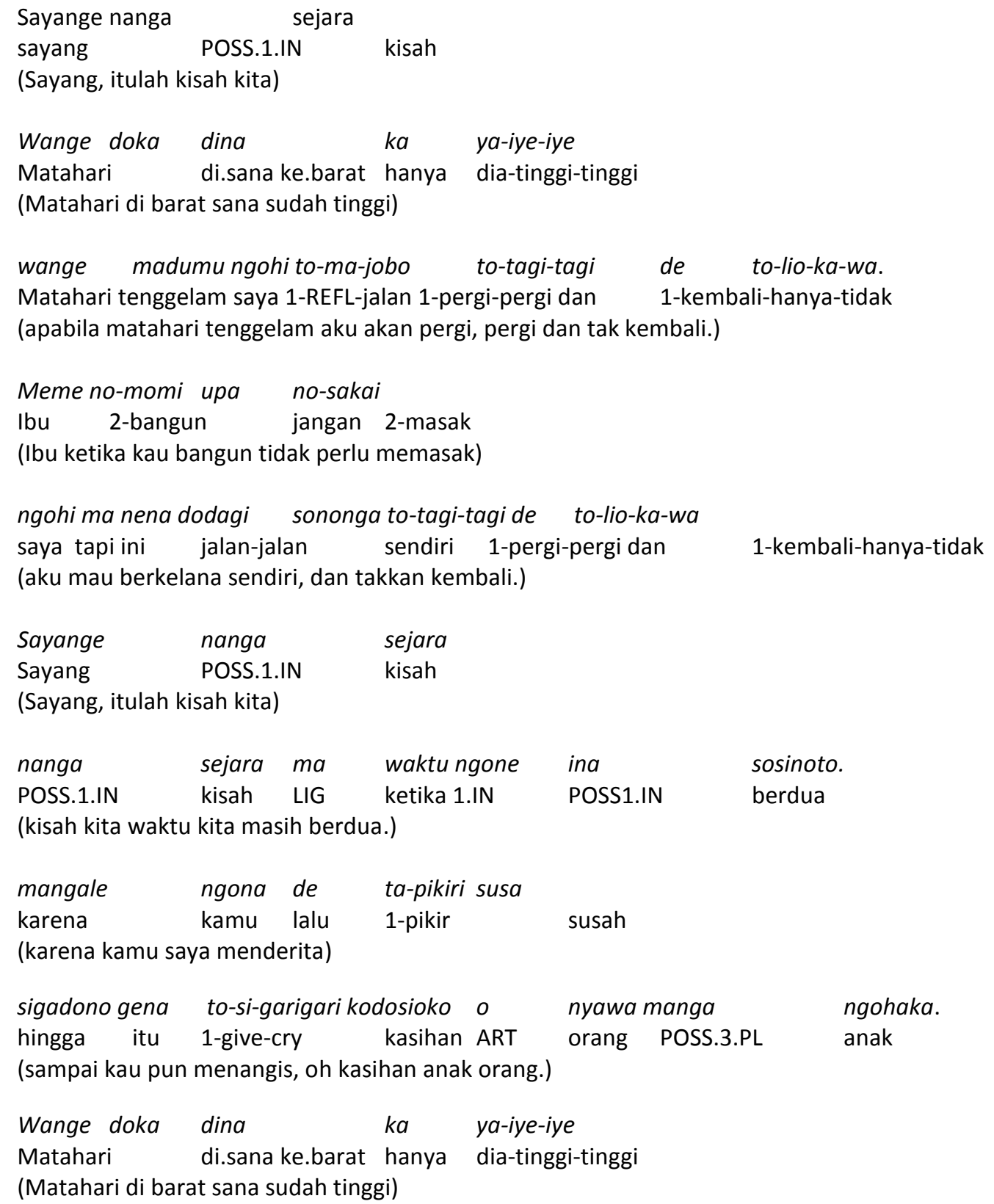


wange madumungohito-ma-jobo to-tagi-tagi de to-lio-ka-wa.

Matahari tenggelam saya 1-REFL-jalan 1-pergi-pergi dan 1-kembali-hanya-tidak (apabila matahari tenggelam aku akan pergi, pergi dan tak kembali.)

$\begin{array}{lllll}\begin{array}{l}\text { Sayange } \\ \text { Sayang } \\ \text { (Sayang, itulah kisah kita) }\end{array} & \begin{array}{l}\text { nanga } \\ \text { POSS.1.IN }\end{array} & \begin{array}{l}\text { sejara } \\ \text { kisah }\end{array} & \\ & & & & \\ \text { nanga } & \text { sejara } \text { ma } & \text { waktu ngone } & \text { ina } & \text { sosinoto. } \\ \text { POSS.1.IN } & \text { kisah } \text { LIG } & \text { ketika 1.IN } & \text { POSS1.IN } & \text { berdua }\end{array}$

(kisah kita waktu kita masih berdua.)

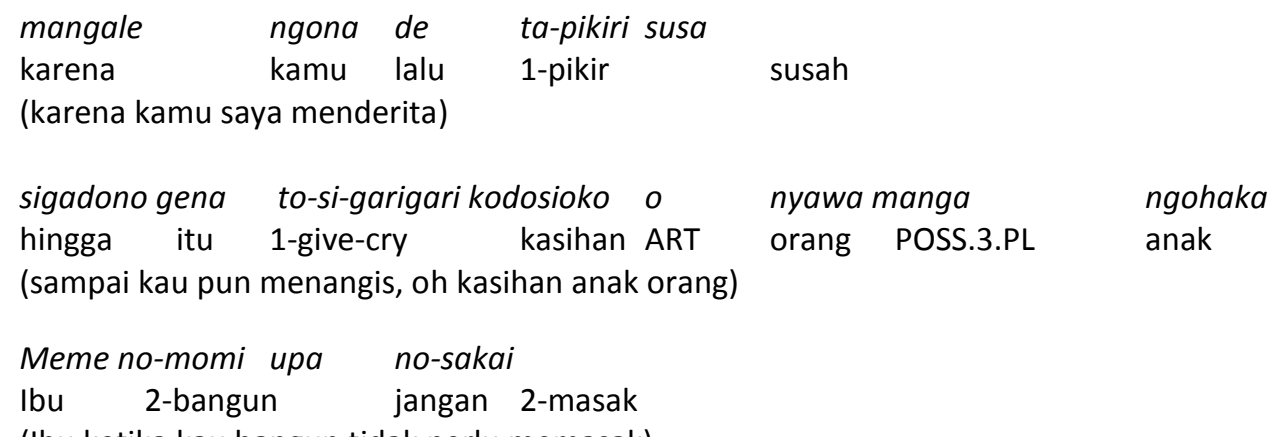

(Ibu ketika kau bangun tidak perlu memasak)

ngohi ma nena dodagi sononga to-tagi-tagi de to-lio-ka-wa saya tapi ini jalan-jalan sendiri 1-pergi-pergi dan 1-kembali-hanya-tidak

(aku mau berkelana sendiri, dan takkan kembali.)

$\begin{array}{lclll}\begin{array}{l}\text { Sayange } \\ \text { Sayang } \\ \text { (Sayang, itulah kisah kita) }\end{array} & \begin{array}{l}\text { nanga } \\ \text { POSS.1.IN }\end{array} & \begin{array}{l}\text { sejara } \\ \text { kisah }\end{array} & \\ \text { nanga } & \text { sejara } \text { ma } & \text { waktu ngone } & \text { ina } & \text { sosinoto } \\ \text { POSS.1.IN } & \text { kisah } \text { LIG } & \text { ketika 1.IN } & \text { POSS1.IN } & \text { berdua }\end{array}$

(kisah kita waktu kita masih berdua.)

$\begin{array}{lllll}\text { mangale } & \text { ngona } & \text { de } & \text { ta-pikiri susa } & \\ \text { karena } & \text { kamu lalu } & \text { 1-pikir } & \text { susah }\end{array}$

(karena kamu saya menderita)

\begin{tabular}{lllll}
\multicolumn{2}{l}{ sigadono gena } & to-si-garigari kodosioko o & nyawa manga & ngohaka \\
hingga itu & 1-give-cry kasihan ART & orang POSS.3.PL & anak
\end{tabular}

(sampai kau pun menangis, oh kasihan anak orang)

Dalam lagu ini dikisahkan seseorang berpamitan meninggalkan keluarga dan kekasihnya untuk berkelana. Sang pengelana berangkat pagi-pagi benar sebelum seisi rumah bangun, terutama sang ibu yang selalu menyiapkan makanan. Ia berpesan agar ibu serta kekasihnya jangan mengharapkan kepulangannya di sore hari, karena ia pergi untuk tidak akan kembali lagi.

(9) wange doka dina kayaiyeiye (matahari di barat sana sudah tinggi)

(10) wange madumu ngohi tomajobo totagitagi de toliokawa. (apabila matahari tenggelam aku akan pergi, pergi dan tak kembali.) 
(11) Meme nomomi upa nosakai

(Ibu ketika kaubangun tidak perlu memasak)

(12) ngohi ma nena dodagi sononga totagitagi de toliokawa (aku mau berkelana sendiri, dan takkan kembali.)

Setiap bahasa merupakan kunci yang dapat membuka pengetahuan lokal tentang rahasia obat tradisional, kearifan lokal tentang cuaca dan iklim, nilai-nilai spiritual dan historis, mitos, dan sebagainya. Kebiasaan atau adat-istiadat sehari-hari juga tersimpan dalam bahasa daerah. Data (9) dan (10) menunjukkan gaya hidup pedesaan yang memulai kerja atau aktivitas lainnya di pagi hari. Di petang hari seseorang biasanya sudah kembali ke rumah. Membawa bekal makan siang yang disiapkan ibu merupakan kebiasaan seperti terlihat pada data (11). Atau jika si pengelana pulang di tengah hari, makanan pun sudah tersedia. Di dalam lagu ini, ritual makan bersama itu tidak terjadi lagi karena si pengelana tidak kembali seperti ditunjukkan oleh data (12).

Ritual atau kebiasaan sehari-hari yang menyatukan keluarga makin langka terjadi ketika modernisasi mulai menggantikan gaya hidup pedesaan. Dewasa ini orang tidak harus bangun pagi-pagi untuk mengawali kegiatan mereka. Makanan siap saji menggantikan kegiatan ibu yang bangun pagi dan sibuk di dapur; beraneka macam makanan dan jajanan dapat diperoleh dengan mudah sewaktu-waktu. Dari perspektif ekolinguistik, cerita tentang kehidupan desa atau daerah pedalaman yang jauh dari konsumerisme merupakan narasi yang harus dibagikan dan dihidupi terus-menerus atau yang disebut story-we-live-by oleh pegulat ekologi bahasa (Stibbe, 2015) dan peneliti lainnya yang menghubungkan lingkungan hidup dan kajian bahasa serta pemertahanannya (misalnya, Brenzinger \& Heinrich, 2013; Nash \& Mühlhäusler, 2014; Nooteboom \& De Jong, 2010; Norrick, 2011).

Selanjutnya, di balik kisah sedih yang bernuansa putus cinta ini, tidak banyak ditemukan pemaparan tentang lanskap dan lingkungan yang khas tanah Pagu. Tidak terlalu jelas pula mengapa kedua sejoli dalam lagu ini tidak bisa lagi bersatu.

(13)

sayange nanga sejara

(Sayang, itulah kisah kita)

(14)

nanga sejara ma waktu ngone ina sosinoto

(kisah kita waktu kita masih berdua)

(15)

mangale ngona de tapikiri susa

(karena kamu aku menderita)

(16)

sigadono gena nosigarigari kodo hioko o nyawa manga ngohaka.

(sampai kau pun menangis, oh kasihan anak orang.) 
Data (13) sampai (16) diulang dua kali. Di sini terlihat bahwa perpisahan sepasang kekasih ini merupakan hal yang berat. Meskipun lagu rakyat ini seperti lagu cinta biasa, terlihat di sini ada banyak harta yang ditinggalkan oleh sang pencerita-pengelana, yakni kekasih, ibu, dan kebiasaan sehari-hari di tanah Pagu. Keterikatan emosi dengan tanah kelahiran dan budaya serta adat-istiadat yang melekat di dalamnya, dalam pandangan ekolinguistik, merupakan hal yang baik dan patut dipertahankan.

\section{PENUTUP}

Berdasarkan hasil analisis atas ketiga lagu daerah Pagu, penelitian ini menyimpulkan tiga hal utama. Pertama, ketiga lagu tersebut memiliki nilai adat dan budaya lokal yang menunjukkan jatidiri kelompok etnis Pagu, meskipun sudah jarang dikenal di tengah masyarakat secara umum. Hal ini karena bahasa Pagu sudah jarang digunakan oleh masyarakat Pagu terutama oleh generasi muda. Atas dasar fakta inilah, pengenalan ulang ketiga lagu ini ke tengah-tengah masyarakat Pagu sangatlah penting.

Kedua, analisis Ekolinguistik menunjukkan adanya kedekatan masyarakat Pagu pada alam sekitarnya meskipun kadang-kadang alam juga dianggap sebagai penghambat perjalan manusia dan harus ditaklukkan. Ketiga, dari segi penyebaran/distribusi, ketiga lagu banyak dipengaruhi oleh bahasa Ternate dan juga bahasa-bahasa daerah lain di Halmahera Utara seperti bahasa Tobelo, Modole, Galela dan Loloda. Bahasa-bahasa ini dipakai oleh lebih banyak orang dan mempengaruhi bahasa Pagu. Selama masih ada penggunanya dan terjadi interaksi yang intensif antar pengguna, pemertahanan bahasa Pagu masih dapat dilakukan. Perawatan dan pengenalan kembali budaya lokal seperti lagu-lagu daerah merupakan salah satu cara untuk meningkatkan penggunaan bahasa Pagu sehingga kepunahannya dapat dicegah.

\section{DAFTAR PUSTAKA}

Albury, N. J. (2016). Defining Māori language revitalisation: A project in folk linguistics. Journal of Sociolinguistics. https://doi.org/10.1111/josl.12183

Amal, M. A. (2016). Kepulauan rempah-rempah. Jakarta: Kepustakaan Populer Gramedia.

Brenzinger, M., \& Heinrich, P. (2013). The return of Hawaiian: Language networks of the revival movement. Current Issues in Language Planning. https://doi.org/10.1080/14664208.2013.812943

Chala Teresa, G., \& Dagim Raga, H. (2018). Oromo Oral Literature for Environmental Conservation: A Study of Selected Folksongs in East and West Hararghe Zones. Humanities, 7(4), 94. https://doi.org/10.3390/h7040094

Eliasson, S. (2015). The birth of language ecology: Interdisciplinary influences in Einar Haugen's "The ecology of language." Language Sciences. 50(2) https://doi.org/10.1016/j.langsci.2015.03.007 
Guérin, V. (2008). Writing an endangered language. Language Documentation \& Conservation.

Hinton, L. (2001). Language Revitalization. In The Green Book of Language Revitalization in Practice. https://doi.org/10.1016/B978-012349353-8/50003-0

Hinton, L. (2011). Language revitalization and language pedagogy: New teaching and learning strategies. Language and Education. 25(4). https://doi.org/10.1080/09500782.2011 .577220

Hisyam, M., D. Purwoko, Usman, D. P. (2012). Bahasa Pagu: Vitalitas dan Pemertahanannya. Jakarta: PMB-LIPI.

Johnson, H. (2015). Musical ownership and popfolk on Jersey: Sustaining tradition through intervention, technology and creative practice. Journal of World Popular Music. 2(1) https://doi.org/10.1558/jwpm.v2i1.27169

Kingsnorth, P., \& Hine, D. (2009). Uncivilized | The Manifesto.

Lauder, M. R. M. T. (2011). Pengelolaan dan Pemberdayaan Bahasa yang Berpotensi Terancam Punah. Prosiding Seminar Pengembangan Dan Perlindungan Bahasa-Kebudayaan Etnik Minoritas Untuk Penguatan Bangsa, Vol 5. https://doi.org/10.21832/9781853598685-007

Lauder, M. R. M. T. (2018). 4. Obstacles to Creating an Inventory of Languages in Indonesia: A Dialectology Perspective. In Language Diversity in the Pacific. https://doi.org/10.21832/9781853598685-007

McCarter, J., \& Gavin, M. C. (2011). Perceptions of the value of traditional ecological knowledge to formal school curricula: Opportunities and challenges from Malekula Island, Vanuatu. Journal of Ethnobiology and Ethnomedicine. https://doi.org/10.1186/1746-4269-7-38

McCormick, A. (2016). Vanuatu education policy post-2015: "Alternative", decolonising processes for "development." International Education Journal.

Nash, J. (2015). Placenames and ecolinguistics: Some considerations for toponymists. $A A A$ Arbeiten Aus Anglistik Und Amerikanistik.

Nash, J., \& Mühlhäusler, P. (2014). Linking language and the environment: The case of Norf'k and Norfolk Island. Language Sciences. https://doi.org/10.1016/j.langsci.2013.08.004

Nooteboom, G., \& De Jong, E. B. P. (2010). Against “Green Development Fantasies": Resource degradation and the lack of community resistance in the Middle Mahakam Wetlands, East Kalimantan, Indonesia. Asian Journal of Social Science. https://doi.org/10.1163/156853110X490935

Norrick, N. R. (2011). How proverbs mean: Semantic studies in english proverbs. In How Proverbs Mean: Semantic Studies in English Proverbs. https://doi.org/10.2307/415429

Pattikayhatu, J. A. (2012). Bandar Niaga di Perairan Maluku dan Perdagangan RempahRempah Commercial Port in the Moluccas Territorial Water and Spice Trade. Kapata Arkeologi.

Perangin-Angin, D. (2013). Meninjau Struktur Peribahasa Pagu: Sebuah Bahasa di Indonesia Timur yang Terancam Punah. Jurnal Masyarakat Dan Budaya, 15(3), 447-474.

Perangin-Angin, D. M. (2018). A descriptive grammar of the Pagu language. Unpublished PhD Thesis, The University of Hong Kong.

Ririmasse, M. N. (2017). Sebelum Jalur Rempah: Awal Interaksi Niaga Lintas Batas di Maluku dalam Perspektif Arkeologi. Kapata Arkeologi. 13(1) https://doi.org/10.24832/kapata.v13i1.388

Rosowsky, A. (2015). Heavenly verses: The role of devotional song in minority language maintenance. The Music of Endangered Languages, 92-99.

Steffensen, S. V., \& Fill, A. (2014). Ecolinguistics: The state of the art and future horizons. Language Sciences. https://doi.org/10.1016/j.langsci.2013.08.003

Stibbe, A. (2015). Ecolinguistic Discourse Analysis. In The International Encyclopedia of 
Language and Social Interaction. https://doi.org/10.1002/9781118611463.wbielsi013

Sunarto, E., Mukarto, F. X., Bismoko, J., \& Dewi, N. (1998). Trilingual Textualization To Deliver Indonesian Local Cultures to High School Students. Language and Language Teaching Journal. https://doi.org/10.24071/llt.2018.210109

Tondo, F. H. (2019). Language and religion: The use of language in Christian liturgy on some border areas of Indonesia. Jurnal Masyarakat Dan Budaya, 20(3), 347-359. https://doi.org/10.14203/jmb.v20i3.593

Vari-Bogiri, H. (2005). A sociolinguistic survey of Araki: A dying language of Vanuatu. Journal of Multilingual and Multicultural Development. 26(1) https://doi.org/10.1080/14790710508668398 